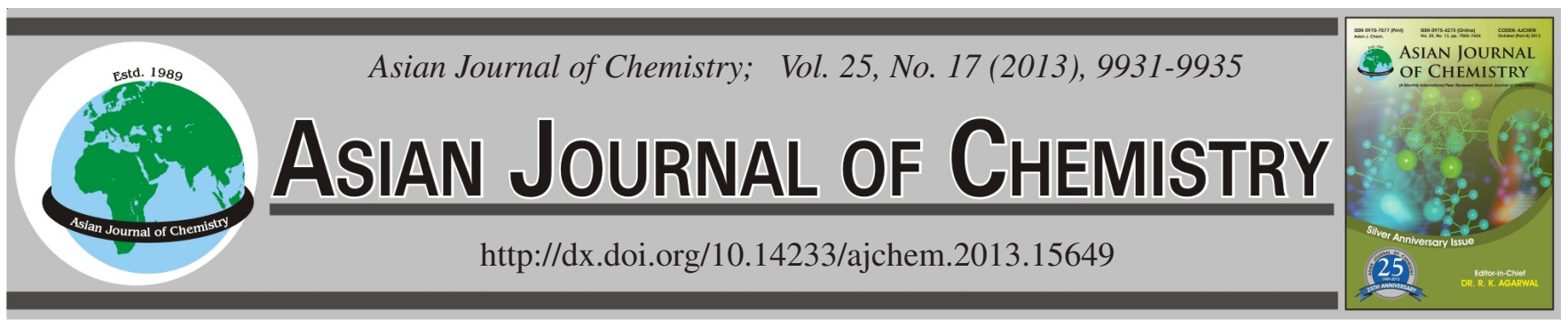

\title{
Synthesis, Characterization, Viscosity and Thermo Analytical Studies of Schiff Base Polymers Derived from 6,6-Methylene bis(1-napthaldehyde)
}

\author{
M.A. Mughal ${ }^{1, *}$, A. Mughal ${ }^{2}$, G. Zuhra $\operatorname{Memon}^{1}$, M.Y. Khuhawar ${ }^{1}$ and Sumera Qureshi ${ }^{2}$
}

${ }^{1}$ Dr. M.A. Kazi Institute of Chemistry, University of Sindh, Jamshoro, Pakistan

${ }^{2}$ Institute of Physics, University of Sindh, Jamshoro, Pakistan

*Corresponding author: E-mail: moina_virgo@ hotmail.com

(Received: 17 April 2013;

Accepted: 28 October 2013)

AJC-14308

\begin{abstract}
Four new Schiff based polymers were synthesized from 6,6-methylene bis (1-napthaldehyde) through polycondensation of 6,6-methylene bis(1-napthaldehyde) with diamines 1,3-propylenediamine, 1,2- propylenediamine, ethylenediamine and urea in 1:1molar ratio. The monomer 6,6-methylene bis(1-napthaldehyde) was prepared by treating 6,6-methylene bis(1-napthaldehyde) with 1,3,5-trioxane in presence of $\mathrm{H}_{2} \mathrm{SO}_{4}$ and $\mathrm{CH}_{3} \mathrm{COOH}$, respectively. The polymers poly[6,6-methylenebis(1-napthaldehyde)1,2-propylenediimine] (PMBNPn), poly[6,6methylenebis(1-napthaldehyde) 1,3-propylenediimine] (PMBNPR), poly[6,6-methylenebis(1-napthaldehyde)ethylenediimine] (PMBNen) and poly[6,6-methylenebis(1-napthaldehyde)urea (PMBNU), were soluble in few organic solvents. The structure of Schiff bases was confirmed by CHN, FTIR, UV-visible spectroscopy, TGA/DTA and viscosity measurements. The polymers showed shift in band position as compared to monomer, due to conversion of carbonyl to azomethine group and the increased values of reduced and intrinsic viscosities than the corresponding monomer attributed to the formation of polymers.
\end{abstract}

Key Words: Dialdehydes, Characterization, Viscosity studies, Thermoanalytical studies, Differential thermogravimetric studies.

\section{INTRODUCTION}

Synthesis of Schiff base polymers have always attracted the researchers due to their vast applications in different fields, such as medicine as antiamoebic agents and due to highly tensile and impact strength. Some advancement has been made to overcome their solubilities in limited solvents by inserting flexible bonding in aromatic rings ${ }^{1-3}$.

Schiff base polymers (SBPs) and their metal complexes have interesting properties due to their nature of binding toxic and heavy metal ions ${ }^{4-7}$ and $^{8-15}$. SBPs have thermal stability similar to polyimides and used in packed columns gas chromatography as solid stationary phase.The monomer 6,6-methylene bis (1-napthaldehyde) (MBN) is prepared by reported method of 5,5-methylene bis(salicylaldehyde) and 5,5-methylene bis(2-hydroxyacetophenone ${ }^{2,16}$. The present study reports the synthesis of four new Schiff base polymers by polycondensation of dialdehyde MBN with four diamines. PMBNPn, PMBNPR, PMBNen and PMBNU.

\section{EXPERIMENTAL}

Urea was recrystallized from ethyl alcohol. Glacial acetic acid (E-Merck,Germany), 1,3,5-trioxane, 1,3-propylenediamine,1,2- propylenediamine, ethylenediamine and Urea (Fluka, Switzerland) were used as received.
Synthesis of 6,6-methylene bis(1-napthaldehyde) (MBN): To a solution of $(69 \mathrm{~mL}) 80 \mathrm{~g}$ of $\alpha$-napthaldehyde and glacial acetic acid $(50 \mathrm{~mL})$ at $90-95^{\circ} \mathrm{C}$ was bubbled pure nitrogen gas to maintain inert atmosphere The solution was added dropwise Trioxane $(7.0 \mathrm{~g})$ dissolved in mixture containing $(0.5 \mathrm{~mL})$ conc. $\mathrm{H}_{2} \mathrm{SO}_{4}$ and $(2.5 \mathrm{~mL})$ glacial acetic acid. The temperature was maintained at $90-95{ }^{\circ} \mathrm{C}$ with constant stirring till the completion of reaction. The mixture was added into $1 \mathrm{~L}$ of ice water and kept overnight, after $24 \mathrm{~h}$ the compound separated as oily layer. The product was added $10 \%$ solution of sodium carbonate and stirring was continued till neutralized. The contents were left for precipitation. After $24 \mathrm{~h}$ the solid was filtered and boiled in acetone for 15-25 $\mathrm{min}$ then was filtered and dried in oven for $7-8 \mathrm{~h}$ at $60-70{ }^{\circ} \mathrm{C}$. Melting point observed was above $350^{\circ} \mathrm{C}$ [yield $=5 \mathrm{~g}, 62.5 \%$ ] Scheme-I.

Synthesis of poly 6,6-methylene bis(1-napthaldehyde) 1,2-propylenediimine (PMBNPn): The 6,6-methylene bis (1napthaldehyde) (3.24 g) was added DMF (40-45 mL) and heated till the compound has completely dissolved. The hot solution was filtered and 1,2-propylenediimine $(0.85 \mathrm{~mL})$ was added to it. The reaction mixture was refluxed on hot plate for the period of 22-23 h. The mixture was concentrated and (45 $\mathrm{mL}$ ) ethyl alcohol was added, light brown precipitates were 


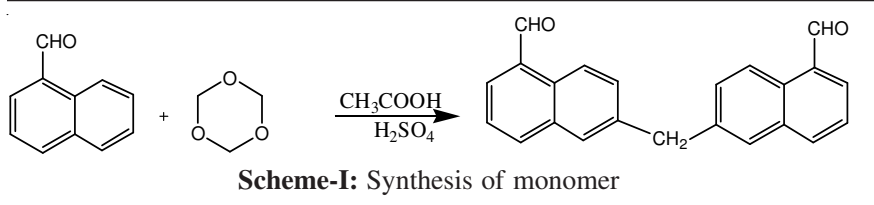

observed, were filtered and finally washed with diethyl ether, acetone and distilled water. The decomposition point was observed as $392^{\circ} \mathrm{C}$ [yield $=3 \mathrm{~g}, 92.5 \%$ ] (Scheme-II).

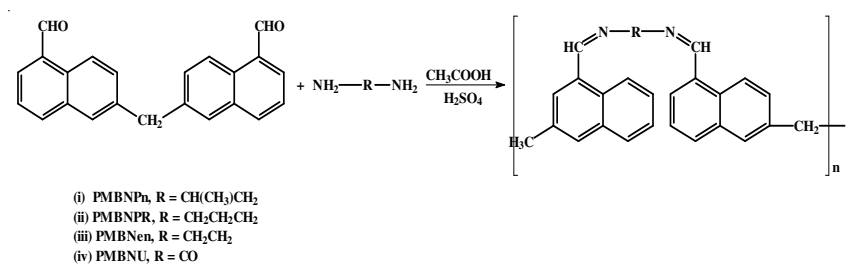

Scheme-II: Synthesis of Schiff base polymers

Synthesis of poly 6,6-methylene bis(1-napthaldehyde) 1,3-propylenediimine (PMBNPR): The 6,6-methylene bis(1-napthaldehyde) (3.24 g) was added DMF (30-35 mL) and through constant stirring and heating the compound completely dissolved; 1,3 -propylenediimine $(0.842 \mathrm{~mL})$ was added into the filtered hot solution of bis(1-napthaldehyde) and refluxed for (22-23) h. The mixture was concentrated and precipitation occurred due to addition of ethyl alcohol (25-30 $\mathrm{mL})$, brownish precipitate were filtered and washed with di ethyl ether acetone and finally with distilled water. The decomposition point was observed as $389^{\circ} \mathrm{C}$ [yield $=2.5 \mathrm{~g}$, $7.1 \%$ ] Scheme-II.

Synthesis of poly 6,6-methylene bis(1-napthaldehyde) ethylenediimine (PMBNen): The 6,6-methylene bis(1napthaldehyde) (3.24 g) was dissolved in DMF (30-45 mL). Ethylenediimine $(0.675 \mathrm{~mL})$ was poured into filtered solution of bis(1-napthaldehyde). The reaction product was refluxed for the period of $22 \mathrm{~h}$. The mixture was concentrated and (35$40 \mathrm{~mL}$ ) ethyl alcohol was added, light brown precipitate recovered was filtered, washed with di ethylether, ethyl alcohol and distilled water. The compound decomposed at $390{ }^{\circ} \mathrm{C}$ [yield $=2.5 \mathrm{~g}, 77.1 \%$ ] Scheme-II.

Synthesis of poly 6,6-methylene bis(1-napthaldehyde) urea (PMBNU): The 6,6- methylene bis(1- napthaldehyde) $(3.24 \mathrm{~g})$ was dissolved in DMF (30-45 $\mathrm{mL})$ and heated till dissolved. hot solution was filtered, Urea $(0.60 \mathrm{~g})$, dissolved in DMF (4 mL )was added into it. The reaction mixture was refluxed for $22 \mathrm{~h}$, product formed containing solvent was concentrated to its half volume till the appearance of light brownish precipitate, which were recovered after addition of $30 \mathrm{~mL}$ ethyl alcohol. Product was filtered, washed with acetone, diethylether and distilled water. The compound decomposed at $385^{\circ} \mathrm{C}$ ] Scheme-II.

The elemental microanalysis was conducted at HEJ, research institute of chemistry, University of Karachi, Pakistan. The IR spectra were recorded on Nicolet Avatar 330 FT-IR (Thermo Nicolet Electron corporation USA) with Atanulated total reflectance (ATR) accessory smart partner ranging 4000$600 \mathrm{~cm}^{-1}$. UV-visible spectrophotometric analysis was carried out in DMF on a double beam Hitachi 220 spectrophotometer (Hitachi (PVT) Tokyo, Japan, with dual $1 \mathrm{~cm}$ silica cuvettes within 185-700 nm. Thermogravimetry and differential thermogravimetric analysis was carried on Pyris DiamondTGA/ DTA (Perkin-Elmer, Japan) analyzer from room temperature to $800^{\circ} \mathrm{C}$ with a nitrogen flow rate of $5 \mathrm{~mL} / \mathrm{min} .2 \mathrm{mg}$ sample was placed each time in platinum crucible, recorded against alumina as reference with heating rate of $20^{\circ} \mathrm{C} / \mathrm{min}$.

The viscosity measurements of monomer and respective Schiff base polymers in DMF with $0.024-0.064 \mathrm{~g} / \mathrm{dl}$ with a temperature range from $283-323 \mathrm{~K}$ with a $10 \mathrm{~K}$ interval, using a suspended level viscometer (TechnoASTM 445).

\section{RESULTS AND DISCUSSION}

The dialdehyde 6,6-methylene bis(1-napthaldehyde) (MBN) was prepared by using the reported method for the preparation of 5,5-methylene bis(salicylaldehyde) and 5,5methylene bis(2-hydroxyacetophenone $)^{2,16,17}$. The structure of monomer was confirmed by elemental analysis. The results of elemental analysis correlated to the expected values (Table1) and supports the formation of polymers. The monomer MBN was further condensed with four different diamines, namely 1,2-propylenediimine (PMBNPn), 1,3-propylenediimine (PMBNPR), (PMBNen) and (PMBNU), respectively. The results of elemental analysis of polymers PMBNPn, PMBNPR, PMBNen and PMBNU derived from MBN are in good aggrement with the expected values. Recrystallization of the Schiff base polymers was not accomplished due to their poor solubility in common organic solvents (Table-2). The FTIR of MBN indicate a strong characterstic peak of carbonyl stretch $v(C=O)$ vibrations at $1700 \mathrm{~cm}^{-1}$. The peak in the respective polymers appeared as a weak band of low intensity due to end on group. The polymers PMBNPn, PMBNPR, PMBNen and PMBNU indicated a strong characteristic band with in 1660$1620 \mathrm{~cm}^{-1}$ due to $\mathrm{v}(\mathrm{C}=\mathrm{N})$ vibrations and support its formation. A band at $1720 \mathrm{~cm}^{-1}$ is observed for polymer PMBNU due to $\mathrm{v}(\mathrm{C}=\mathrm{O})$ group contributed from urea. The monomer and respective polymers indicated bands within 1440-1580 $\mathrm{cm}^{-1}$ due to $v(\mathrm{C}=\mathrm{C})$ vibrations. A weak to medium intensity bands of $\mathrm{CH}$ vibration and ring breathing was observed between $1060-810 \mathrm{~cm}^{-1}$, respectively (Fig. 1). The results of spectroscopic

TABLE-1

CHN ELEMENTAL MICROANALYSIS

\begin{tabular}{lccc|ccc}
\multicolumn{1}{c}{ Compounds } & \multicolumn{3}{c|}{ Calcd. (\%) } & \multicolumn{3}{c}{ Experimental (\%) } \\
\cline { 2 - 7 } & $\mathrm{C}$ & $\mathrm{H}$ & $\mathrm{N}$ & \multicolumn{2}{c}{$\mathrm{C}$} & $\mathrm{H}$ \\
\hline 6,6-Methylene bis(1-napthaldehyde) MBN & 85.16 & 4.90 & - & 86.80 & 5.21 & - \\
Poly6,6-methylene bis(1-napthaldehyde)1,2propylenediimine (PMBNPn) & 86.20 & 5.60 & 7.80 & 86.16 & 5.25 & 6.99 \\
Poly6,6-methylene bis(1-napthaldehyde)1,3propylenediimine (PMBNPR) & 86.21 & 5.60 & 7.81 & 85.90 & 5.65 & 7.00 \\
Poly6,6-methylene bis(1-napthaldehyde)ethylenediimine (PMBNen) & 86.01 & 5.59 & 6.95 & 85.92 & 5.67 & 6.99 \\
Poly6,6-methylene bis(1-napthaldehyde) UREA (PMBNU) & 84.02 & 4.44 & 7.34 & 83.89 & 4.35 & 6.90 \\
\hline
\end{tabular}




\begin{tabular}{|c|c|c|c|c|c|c|c|c|}
\hline \multicolumn{9}{|c|}{$\begin{array}{l}\text { TABLE-2 } \\
\text { Solubility }(a, b) \text { OF MBN AND SCHIFF BASE POLYMERS IN VARIOUS SOLVENTS }\end{array}$} \\
\hline Compounds & $\mathrm{H}_{2} \mathrm{O}$ & $\mathrm{CH}_{3} \mathrm{OH}$ & $\mathrm{C}_{2} \mathrm{H}_{5} \mathrm{OH}$ & $\mathrm{CHCl}_{3}$ & Acetone & $n$-hexane & Ether & DMF \\
\hline MBN & - & - & - & - & \pm & - & - & \pm \\
\hline PMBNPn & - & - & - & \pm & \pm & - & - & \pm \\
\hline PMBNPR & - & - & - & \pm & \pm & - & - & \pm \\
\hline PMBNen & - & - & - & \pm & \pm & - & - & \pm \\
\hline PMBNU & - & - & - & \pm & \pm & - & - & - \\
\hline
\end{tabular}

studies in UV-visible region in DMF as a solvent are shown in (Table-3). The monomer MBN indicates three bands within $251-353 \mathrm{~nm}$ due to $\pi-\pi^{*}$ transitions in benzenoid or napthyl ring systems and carbonyl $\pi$ electrons with molar absorptivities 19011, 11890 and $7320 \mathrm{~L} \mathrm{~mol}^{-1} \mathrm{~cm}^{-1}$. The polymers PMBNPn, PMBNPR, PMBNen and PMBNU in (Fig. 2) indicates four bands, a shift in band position and an origin of a new band as compared to monomer MBN, may be due to chromophores of conjugated azomethine, due to polycondensation.

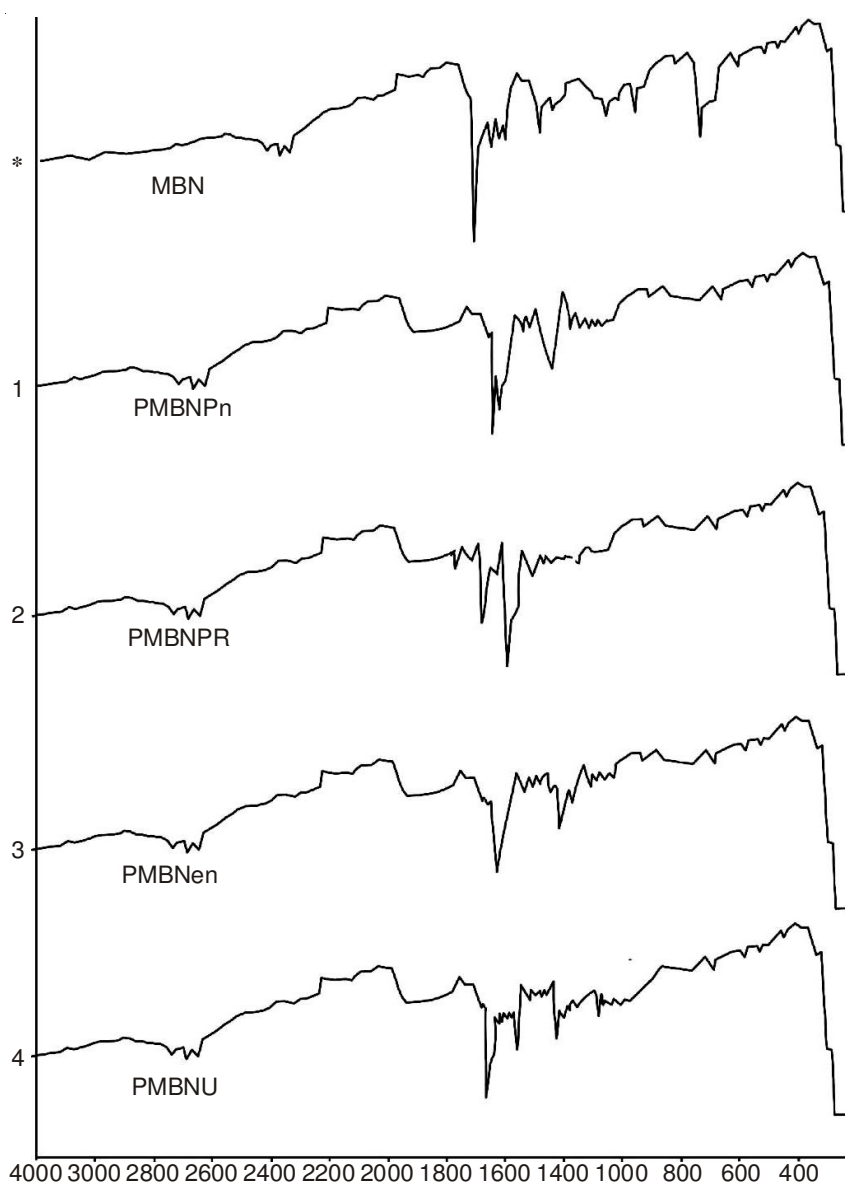

Fig. 1. FTIR analysis of MBN, PMBNen, PMBNPn, PMBNPR, PMBNU* MBN, 1 PMBNPn, 2 PMBNPR, 3 PMBNen, 4 PMBNU

For viscometric measurements, $15 \mathrm{~mL}$ solution was taken for all the runs and average flow time of three readings were noted, along with the flow time of solvent. To maintain and control the temperature Gallen kemp viscometer water bath was used. The reduced viscosity $\left(\eta_{\text {red }}\right)$ was calculated by dividing specific viscosity $\left(\eta_{\mathrm{sp}}\right)$ by concentration in $(\mathrm{g} / \mathrm{dl})$. The intrinsic viscosity $(\eta)$ was calculated from equation $\eta_{\text {red }}$

\begin{tabular}{|c|c|}
\hline RESULTS O & $\begin{array}{l}\text { TABLE-3 } \\
\text { ECTROSCOPIC STUDIES IN DMF AS SOLVEN }\end{array}$ \\
\hline Compound & $\lambda_{\max } \mathrm{nm}(\varepsilon)$ \\
\hline 1. MBN & $\begin{array}{l}25119011 \mathrm{~L} \mathrm{~mol}^{-1} \mathrm{~cm}^{-1} \\
31511890 \mathrm{~L} \mathrm{~mol}^{-1} \mathrm{~cm}^{-1} \\
3537320 \mathrm{~L} \mathrm{~mol}^{-1} \mathrm{~cm}^{-1}\end{array}$ \\
\hline & $\lambda \mathrm{nm} \varepsilon 1 \%$ \\
\hline 2. PMBNU & 257(289.2), 305(121), 395(121.75), 400(106.5) \\
\hline 3. PMBNPR & 252(322.8), 309(213.3), 380 (111.4), 405(106.5) \\
\hline 4. PMBNen & 261(299), 304(112.2), 370(77), 400(120.5) \\
\hline 5. PMBNPn & 251(324.7), 314 (111.2), 370 (78), 410 (121.3) \\
\hline
\end{tabular}

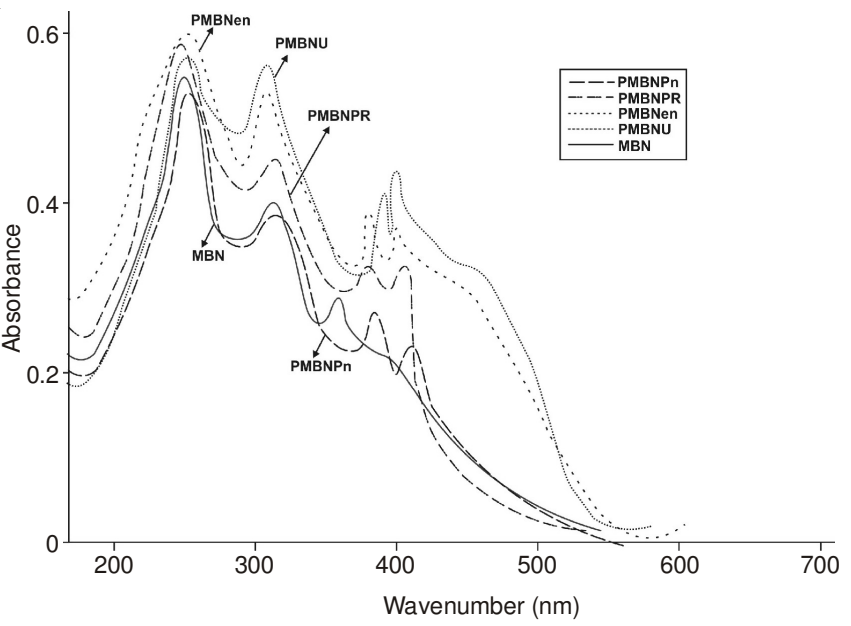

Fig. 2. UV-Visible spectra of PMBNen, PMBNPn, PMBNPR, PMBNU

$=[\eta]+\mathrm{kH}[\eta] 2 \mathrm{C}$, the reduced viscosity was plotted against concentration and extrapolating to zero concentration. The polymers indicated higher values of intrinsic viscosity than the corresponding monomer MBN and are added point in its formation. All thermodynamic parameters of monomer as well as the polymers were calculated. Gibbs free energy $(\Delta G)$ was calculated by using eq. $\Delta \mathrm{G}=2.303 \mathrm{RT} \log \left(\eta_{\mathrm{abs}} / 10-3\right)$, $\mathrm{R}$ is a

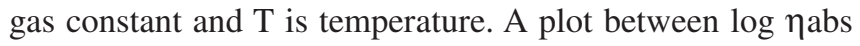
and $1 / \mathrm{T}$ was linear. The heat of activation of viscous flow $(\Delta \mathrm{Hv})$ were calculated from slope (slope $\times R$ ). The entropy of activation of viscous flow $(\Delta \mathrm{Sv})$, was calculated from equation $(\Delta \mathrm{Gv})=\Delta \mathrm{Hv}-\mathrm{T} \Delta \mathrm{Sv}($ Table-4) .

TABLE-4

INTRINSIC VISCOSITY VALUES OF MONOMER (MBN) AND SCHIFF BASE POLYMERS (dl/g)

\begin{tabular}{cccccc}
\hline Compound & 283 & 293 & 303 & 313 & 323 \\
\hline MBN & 0.3000 & 0.2660 & 0.2410 & 0.2110 & 0.1940 \\
PMBNU & 0.4430 & 0.3810 & 0.3630 & 0.3420 & 0.3260 \\
PMBNPR & 0.4321 & 0.3995 & 0.3815 & 0.3720 & 0.3422 \\
PMBNen & 0.4111 & 0.3720 & 0.3510 & 0.3320 & 0.3200 \\
PMBNPn & 0.4554 & 0.4476 & 0.4332 & 0.4369 & 0.4320 \\
\hline
\end{tabular}




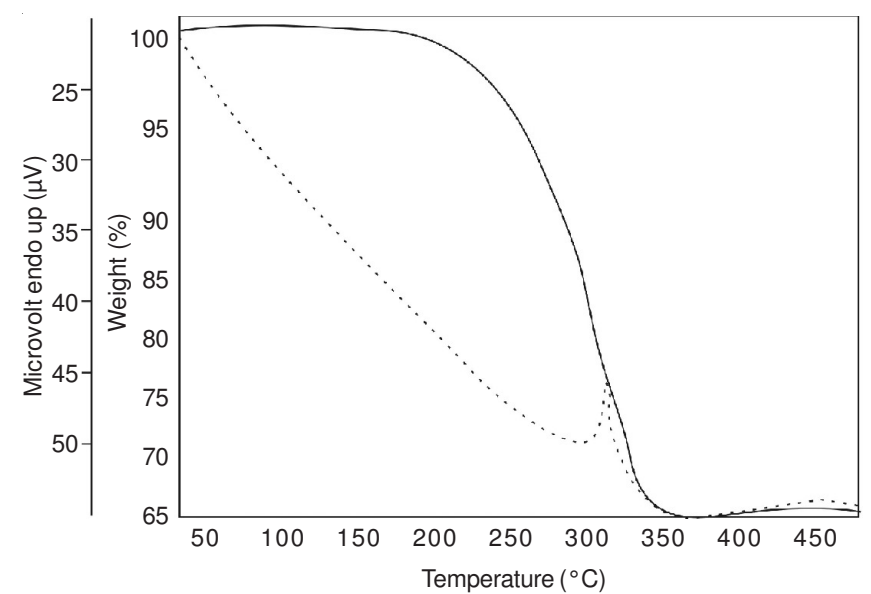

Fig. 3. TGA and DTA of MBN

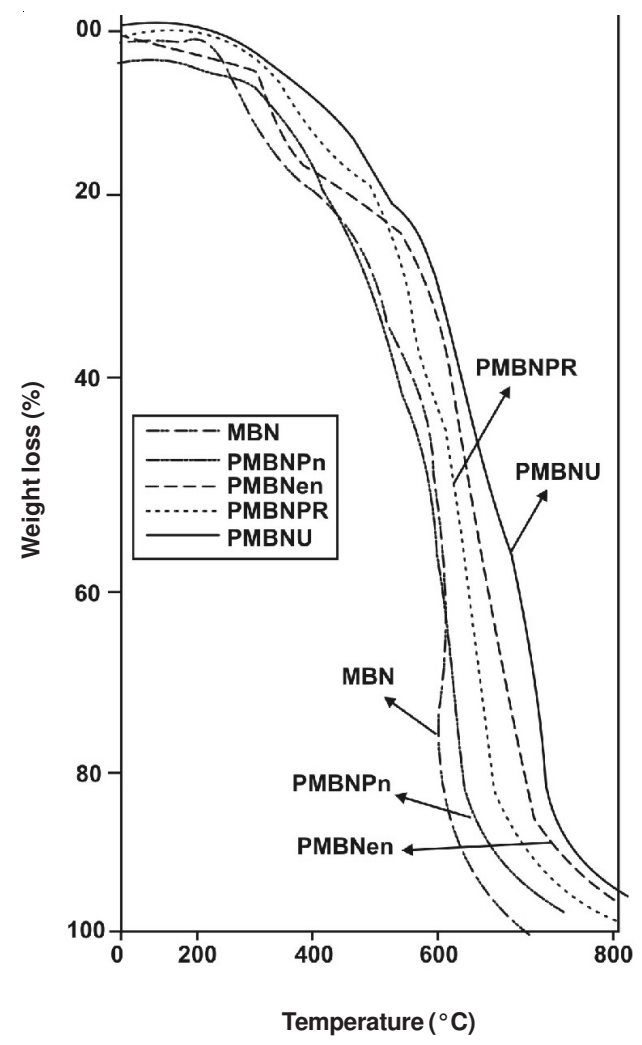

TGA of Shiff base Polymers

Fig. 4. TGA of PMBNen, PMBNPn, PMBNPR, PMBNU

The results of thermogravimetric (TG) analysis recorded, (Fig. 3) showed that for the monomer MBN, weight loss started at $200{ }^{\circ} \mathrm{C}$ and $100 \%$ loss was observed at $740^{\circ} \mathrm{C}$ and primary weight loss of $36 \%$ was observed at $200-489^{\circ} \mathrm{C}$, secondary

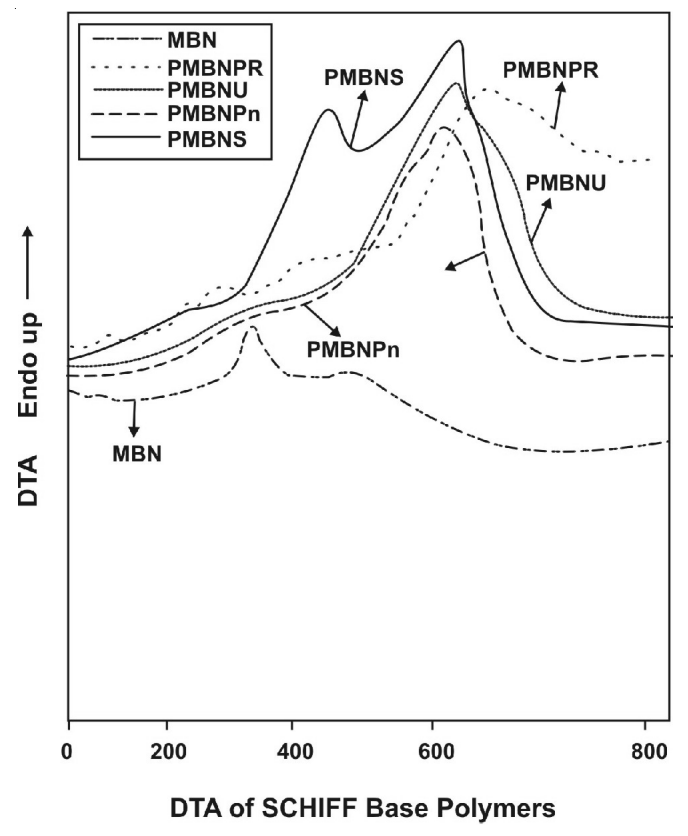

Fig. 5. DTA of PMBNen, PMBNPn, PMBNPR, PMBNU

weight loss of $27 \%$ occurred within $489-595^{\circ} \mathrm{C}$, tertiary weight loss of $33 \%$ at $590-800{ }^{\circ} \mathrm{C}$, followed by maximum and rapid weight loss at $600^{\circ} \mathrm{C}$ (Table-5). The DTA of MBN indicated a strong well defined endotherm at $310^{\circ} \mathrm{C}$ and may be attributed to melting of the monomer. The TGA of polymer PMBNPR (Fig. 4) showed weight loss in three stages initial loss of $9 \%$ within $240-255^{\circ} \mathrm{C}$, secondary loss of $16 \%$ within temperature range of $410-590^{\circ} \mathrm{C}$, this is followed by rapid and total weight loss of $97 \%$ upto temperature $800{ }^{\circ} \mathrm{C}$, with a maximum rate of loss by $679^{\circ} \mathrm{C}$. The DTA of PMBNPR showed three endotherms first one at $189^{\circ} \mathrm{C}$ due to less quantity of solvent left in the sample and at $659^{\circ} \mathrm{C}$ and at $739^{\circ} \mathrm{C}$ which could be attributed to the decomposition of compound. The TGA of polymer PMBNU showed initial weight loss of $10 \%$ between 235-288 ${ }^{\circ} \mathrm{C}$, secondary loss of $18 \%$ within $478-548^{\circ} \mathrm{C}$, followed by tertiary and total loss $100 \%$ at $678^{\circ} \mathrm{C}$ with a maximum of rate of loss at $598^{\circ} \mathrm{C}$. The DTA showed (Fig. 5) three endotherms at $178{ }^{\circ} \mathrm{C}$, due to loss of solvent second one at $259^{\circ} \mathrm{C}$ due to vaporisation, or voltalization and last at $659^{\circ} \mathrm{C}$ owing to its decomposition (Table-6). The TGA of polymer PMBNPn showed weight loss in three stages, initial weight loss of 11.5 $\%$ between $159-274^{\circ} \mathrm{C}$ secondary loss of $16.5 \%$ between 378 $399^{\circ} \mathrm{C}$, followed by tertiary and total weight loss $97 \%$ at 719 ${ }^{\circ} \mathrm{C}$ with maximum rate of weight loss at $548{ }^{\circ} \mathrm{C}$. The DTA showed two endotherms, a weak endotherm at $149^{\circ} \mathrm{C}$ is due to less quantity of solvent left in sample and a sharp endothermal $594^{\circ} \mathrm{C}$ due to decomposition of polymer. The TGA of polymer

\begin{tabular}{|c|c|c|c|c|c|}
\hline \multicolumn{6}{|c|}{$\begin{array}{c}\text { TABLE-5 } \\
\text { TGA ENDOTHERM }\end{array}$} \\
\hline Characterization & MBN & PMBNU & PMBNPR & PMBNen & PMBNPn \\
\hline 1. Primary wt loss (\%) & 36 & 10 & 9 & 3.8 & 11.5 \\
\hline Temperature $\left({ }^{\circ} \mathrm{C}\right)$ & $200-489$ & $235-268$ & $240-255$ & $189-337$ & $159-274$ \\
\hline 2. Sec wt loss $(\%)$ & 27 & 18 & 16 & - & 16.5 \\
\hline Temperature $\left({ }^{\circ} \mathrm{C}\right)$ & $489-595$ & $479-548$ & $410-590$ & - & $378-399$ \\
\hline 3. Tertiary wt loss $(\%)$ & 33 & 100 & 97 & 95 & 97 \\
\hline 4.Max and rapid loss $\left({ }^{\circ} \mathrm{C}\right)$ & 600 & 598 & 679 & 589 & 548 \\
\hline
\end{tabular}


PMBNen showed weight loss in two stages primary loss of $3.8 \%$ within temperature $189-337^{\circ} \mathrm{C}$, followed by total loss of $95 \%$ at $689{ }^{\circ} \mathrm{C}$ with rapid loss at $589{ }^{\circ} \mathrm{C}$. The DTA of compound showed two endotherms first one at $359^{\circ} \mathrm{C}$ and a strong endotherm at $599^{\circ} \mathrm{C}$ was may be due to decomposition of polymer.

\begin{tabular}{cccccc}
\hline \multicolumn{7}{c}{ TABLE-6 } \\
DTA ENDOTHERM $\left({ }^{\circ} \mathrm{C}\right)$ \\
\hline Characterization & MBN & PMBNU & PMBNPR & PMBNen & PMBNPn \\
\hline & 310 & 178 & 189 & 359 & 149 \\
& - & 259 & 659 & 599 & 594 \\
& - & 659 & 739 & - & - \\
\hline
\end{tabular}

\section{Conclusion}

Four Schiff based polymers were synthesized by condensing these with monomer MBN, all were characterized through elemental microanalysis, FTIR, UV-visible, viscosity and thermodynamic parameters. The polymers showed less solubility in majority of organic solvents and that could be regarded as their major drawback. The polymers showed good thermal stability, which could be analyzed by observing their melting points.

\section{REFERENCES}

1. M. Grigoras and C.O. Catanescu, J. Macromol. Sci., C44, 131 (2004).

2. M.Y. Khuhawar, A.H. Channar and S.W. Shah, Eur. Polym. J., 34, 133 (1998).
3. S. Banerjee, P.K. Gutch and C.J. Saxena, Des. Monomer Polym., 2, 135 (1999).

4. R. Grünes and W. Sawodny, J. Chromatogr. A, 322, 63 (1985).

5. Y. Sasaki, L.L. Walker, E.L. Hurst and C.U. Pittman Jr., J. Polym. Sci., Polym. Chem. Ed., 11, 1213 (1973).

6. F. Galbrecht, B.S. Nehls D. Weher, T. Farrel and U. Scherf, Chem. Commun., 2758 (2004).

7. C.S. Kwok, L. Yu, H.T. Sham and C. Mingche, J. Chem. Commun., 2378 (2005).

8. H. Chen, J.A. Cronin and R.D. Archer, Macromolecules, 27, 2174 (1994).

9. H. Chen, J.A. Cronin and R.D. Archer, Macromolecules, 28, 1609 (1995).

10. H. Chen, J.A. Cronin and R.D. Archer, Macromolecules, 29, 1957 (1996).

11. M. Vilas, B. Santos, I.C. Henderson, M.J. Freire, C. Hillman, A.R. Chen, J.A.H. Cronin and R.D. Archer, Langmuir, 19, 7460 (2003).

12. A. Anthonysamy and S. Balasubramanian, Inorg. Chem. Commun., 8, 908 (2005).

13. P. Audebert, P. Capdevielle, and M. Maumy, New J. Chem., 16, 697 (1992).

14. J.N. Wilde, A.J. Wigman, J. Nagel, U. Oertal, A. Beeby, B. Tanner and M.C Pelty, Acta Polym., 49, 249 (1998).

15. M. Palumbo, A. Cosani, M. Terbojevich and E. Peggion, J. Am. Chem. Soc., 99, 939 (1977).

16. M.Y. Khuhawar, A. Shah and M.A. Mughal, Chin. J. Polym. Sci., 25, 399 (2007).

17. A.D. Pomogailo and I.E. Uflyand, J. Mol. Catal., 55, 429 (1989). 